\title{
Ensino remoto na pandemia da Covid-19 e os desafios e oportunidades na visão de professores de escolas do interior de Mato Grosso
}

\author{
Remote teaching in the Covid-19 pandemic and the challenges and opportunities in the view of \\ teachers from schools in the interior of Mato Grosso \\ La enseñanza a distancia en la pandemia del Covid-19 y los desafíos y oportunidades a la vista de \\ los maestros de las escuelas del interior de Mato Grosso
}

Recebido: 29/121/2021 | Revisado: 03/01/2022 | Aceito: 12/01/2022| Publicado: 14/01/2022

\author{
Janaina da Silva Costa Bernardino \\ ORCID: https://orcid.org/0000-0002-6712-7378 \\ Secretaria de Educação do Estado do Mato Grosso, Brasil \\ Escola Estadual Prefeito Alfredo de Araújo Granja, Brasil \\ E-mail: janainacosta_2008@hotmail.com \\ Eliédna Aparecida Rocha de Oliveira \\ ORCID: https://orcid.org/0000-0002-2207-3775 \\ Secretaria de Educação do Estado do Mato Grosso, Brasil \\ Escola Estadual da Policia Militar "Tiradentes", Brasil \\ E-mail: eliednarochadeoliveira@outlook.com \\ Anderson Fernandes de Miranda \\ ORCID: https://orcid.org/0000-0001-9251-572X \\ Universidade do Estado de Mato Grosso, Brasil \\ E-mail: anderson@unemat.br \\ José Wilson Pires Carvalho \\ ORCID: https://orcid.org/0000-0002-5969-5105 \\ Universidade do Estado de Mato Grosso, Brasil \\ E-mail: jwilsonc@unemat.br
}

\begin{abstract}
Resumo
Este estudo teve como objetivo discutir e compreender os desafios e oportunidades que o ensino remoto em tempo de pandemia proporcionou a um grupo de professores de escolas públicas do estado de Mato Grosso. Os participantes da pesquisa foram um grupo de professores de diferentes localidades e escolas, do interior do Estado de Mato Grosso. Os participantes responderam a um questionário via google formulários, contendo perguntas abertas e fechadas. A análise dos dados foi realizada usando o método indutivo. O referido estudo mostra que as oportunidades vivenciadas foram referentes a aprendizagem do uso de recursos digitais para o ensino e pela vivência de experiências de conhecer melhor os alunos, que na visão dos participantes torna o ensino mais humano. Os desafios na visão dos professores consistiram desde a formação continuada dos professores até o acesso a essas tecnologias que viabilizaram o ensino remoto. Esses resultados mostram que mesmo estando na era da tecnologia, o ensino remoto trouxe desafios ao começar pela utilização das tecnologias digitais no contexto do ensino remoto. Pois, muitos dos professores não possuíam formação voltada para o uso do ambiente virtual de aprendizagem (AVA). De modo que muitos professores usaram diversos recursos, sendo esses, aquele que tinham maior domínio, tal como: aplicativo de mensagem instantânea, vídeos, AVA e outros. Por fim, o presente estudo mostra que o ensino remoto possibilitou novas aprendizagem sobre tecnologias digitais aos professores e tendo como um dos principais desafios na oferta do ensino remoto, o de atrair a atenção e assiduidade dos alunos durante as aulas.
\end{abstract}

Palavras-chave: Desafios; Educação; Ensino remoto; Oportunidades; Tecnologias.

\begin{abstract}
This study aimed to discuss and understand the challenges and opportunities that remote teaching in a time of pandemic provided to a group of teachers from a public school in the state of Mato Grosso. The research participants were a group of teachers from different locations and schools in the interior of the State of Mato Grosso. Participants answered a questionnaire via google forms, containing open and closed questions. Data analysis was performed using the inductive method. This study shows that the opportunities experienced were related to learning the use of digital resources for teaching and the experience of getting to know the students better, which, in the view of the participants, make teaching more human. The challenges in the view of teachers ranged from teacher training to access to these technologies that made remote teaching possible. These results show that even being in the era of technology, remote teaching brought challenges when starting to use digital technologies in the context of remote teaching, as many of the
\end{abstract}


teachers did not have training focused on the use of the virtual learning environment (VLE). So many teachers used several resources, being these, the one that had greater domain, such as: instant messaging application, videos, VLE and others. Finally, the present study shows that remote teaching enabled new learning about digital technologies for teachers and having as one of the main challenges in the offer of remote teaching, to attract the attention and assiduity of students during classes.

Keywords: Challenges; Education; Remote teaching; Opportunities; Technologies.

\section{Resumen}

Este estudio tuvo como objetivo discutir y comprender los desafíos y oportunidades que la enseñanza a distancia en tiempos de pandemia brindaba a un grupo de maestros de una escuela pública del estado de Mato Grosso. Los participantes de la investigación fueron un grupo de profesores de diferentes localidades y escuelas del interior del Estado de Mato Grosso. Los participantes respondieron un cuestionario a través de formularios de Google, que contenía preguntas abiertas y cerradas. El análisis de los datos se realizó mediante el método inductivo. El estudio mencionado muestra que las oportunidades vividas estuvieron relacionadas con el aprendizaje del uso de los recursos digitales para la docencia y la experiencia de conocer mejor a los estudiantes, lo que, a juicio de los participantes, hace que la enseñanza sea más humana. Los desafíos en la visión de los maestros iban desde la formación del profesorado hasta el acceso a estas tecnologías que hicieron posible la enseñanza a distancia. Estos resultados muestran que aún estando en la era de la tecnología, la enseñanza a distancia trajo desafíos al comenzar a utilizar las tecnologías digitales en el contexto de la enseñanza a distancia, ya que muchos de los maestros no tenían una formación enfocada en el uso del entorno de aprendizaje virtual (AVA). De modo que muchos maestros utilizaron varios recursos, siendo estos, el que mayor dominio tuvo, tales como: aplicación de mensajería instantánea, videos, VLE y otros. Finalmente, el presente estudio muestra que la enseñanza a distancia posibilitó nuevos aprendizajes sobre tecnologías digitales para los maestros y teniendo como uno de los principales desafíos en la oferta de enseñanza a distancia, captar la atención y asiduidad de los estudiantes durante las clases.

Palabras clave: Desafíos; Educación; Enseñanza remota; Oportunidades; Tecnologías.

\section{Introdução}

A palavra educação tem como significado "ação ou efeito de educar, de aperfeiçoar as capacidades intelectuais e morais de alguém: educação formal; educação infantil, dentre outros" (Freire, 1993). A educação está inclusa na sociedade como um todo, e tem passado por inúmeras mudanças e evoluções ao longo do tempo, que de uma forma ou de outra, acaba moldando o homem, e dependendo desse molde, pode se tornar um instrumento de libertação. A evolução da educação está ligada de forma intima com a evolução da sociedade. Para Gadotti (1999), a prática de educar está ligada a muito antes do pensar pedagógico, que pode surgir com o pensar de forma reflexiva sobre a prática pedagógica, por necessidade de sistematizar e organizar em função dos objetivos.

Freire (1993), afirma que a educação tem como base a intervenção, que isso inspira mudanças em uma sociedade, podendo ser na economia, nas relações humanas e na busca pelos direitos, ou seja, "uma sociedade sem educação não evolui", retrocede, estagna, perde sua essência. Diante disso, se faz importante compreender e estudar sobre a importância da Educação, nos seus mais diversos contextos, pois ela vai proporcionar o conhecimento a humanidade, criando perspectivas.

Em março de 2020, a OMS (Organização Mundial da Saúde), emitiu um alerta a nível mundial, sobre uma doença que estava no nível de pandemia, ou seja, ultrapassou os limites territoriais dos continentes, do seu local de origem, essa doença é provocada pelo Sars- Cov-2 ou mais popularmente conhecido como Coronavírus ou COVID-19. Perante essa situação de ameaça a saúde pública, foram tomadas inúmeras medidas de prevenção e contenção no Brasil e no mundo, que definidamente afetaram a educação e inúmeras áreas da sociedade (OMS, 2020; Appenzeller, et al. 2020; Rossi, et al. 2021).

$\mathrm{Na}$ educação, professores se viram diante de uma realidade bem distinta, com uma nova necessidade de enfrentar os novos desafios e fazer o processo de reinventar a metodologia de ensinar. Os professores tiveram que aprender a manusear os mais diversos equipamentos tecnológicos, desde aplicativos até AVA (Ambiente Virtual de Aprendizagem), passando por gravar aulas, editar vídeos, web-aulas e também reformular todo o seu planejamento, tudo isso em um pequeno espaço de tempo para que o ensino remoto fosse implantado, dando assim continuidade aos processos de ensino e aprendizagem. Devido a essas mudanças, começou a surgir inúmeros questionamento, apontamentos sobre como o professor fará para utilizar essas 
tecnologias digitais, e seu papel como educador, suas condições de trabalho, e a pressão psicológica sofrida em meio ao tempo de preparar aula remota e estar em aula remota e sobre o domínio e conhecimento pleno de recursos como o AVA, ampliando assim sua carga de trabalho (Rondini et al., 2020; Valente, et al. 2020; Milani Júnior \& Carvalho, 2020; Oliveira \& Carvalho, 2020; Neves et al., 2021; Rossi, et al. 2021; Oliveira, et al. 2021).

A educação sofreu muitas consequências, desde a paralização das aulas de forma presencial nas escolas tanto públicas quanto privadas, passando a atingir, alunos, pais, professores, fazendo assim uma promoção de aditamento de muitos planos educacionais. Não se pode esquecer que essas consequências, gerou uma mudança na rotina da vida familiar de todos, levando a variações das rotinas de trabalho e suas ocupações. Para isso, foi importante buscar novos meio, métodos e metodologias de ensino e aprendizagem. Para muitos, os aparelhos móveis são considerados de forma histórica um mecanismo de distração em sala de aula, em casa e até mesmo no serviço. No entanto, no momento de pandemia da COVID-19 vivenciado, ele passou de vilão para mocinho. De modo que os recursos eletrônicos, passaram a serem vistos como parceiros por viabilizarem o acesso às informações (Oliveira et al., 2018; Neves et al., 2019; Médici et al., 2020; Pascoin \& Carvalho, 2020; Lima, et al. 2020; Moreira et al., 2020; Carneiro, et al. 2020; Monteiro \& Nantes, 2021; Rossi, et al. 2021).

Neste contexto, o presente estudo teve como objetivo discutir e compreender os desafios e oportunidades que o ensino remoto em tempo de pandemia proporcionou a um grupo de professores de uma escola pública do estado de Mato Grosso. Assim chegando à resposta à pergunta norteadora, que se define da seguinte forma: Quais as oportunidades e desafios que os professores enfrentaram durante a pandemia do COVID-19, no ano de 2020, na visão de professores que lecionam em escolas do interior do Estado de Mato Grosso?

\section{Metodologia}

No presente estudo se faz uma abordagem qualitativa, com características de estudo de caso. Segundo Fiorentini; Lorenzato (2006, p.110) a abordagem qualitativa, "[...] busca investigar e interpretar o caso como um todo orgânico, uma unidade em ação com dinâmica própria, mas que guarda forte relação com seu entorno, o contexto sociocultural [...]". A pesquisa qualitativa é uma experiência individual ou em grupos, que utiliza meios como: entrevistas narrativas em grupos ou individuais, história de vida, grupos focais, observação de participante e pesquisa documental ou bibliográfica (Bunchaft; Gondim, 2004).

No primeiro momento um grupo de professores foi convidado a participarem voluntariamente da pesquisa e após cinco professores aceitarem foi apresentado a eles o termo de livre esclarecido (CEP:4.510.028). Em seguida foi elaborado e aplicado um questionário on-line disponibilizado no Google Forms para cada um dos professores que lecionam em escolas da educação básica do interior do Estado de Mato Grosso. Os professores são formados em áreas de conhecimentos diferentes, alguns dos professores tinha uma grande experiência de anos trabalhados em escolas e até mesmo na gestão escolar e outros que estavam iniciando a lecionar. No ato da pesquisa os professores estavam cursando uma disciplina como aluno especial no Programa de Pós-Graduação de Stricto Senso em Ensino de Ciências e Matemática, da Universidade do Estado de Mato Grosso, de forma online.

O questionário abordou as principais oportunidades e desafios na visão dos professores durante o ensino remoto, na utilização de recurso de tecnologias digitais (Quadro 1). O questionário continha seis questões quatro abertas e duas fechadas (Quadro 1). Segundo Gil (2008, p. 121) o questionário é uma "técnica de investigação composta por um número mais ou menos elevado de questões apresentadas por escrito às pessoas, tendo por objetivo o conhecimento de opiniões, crenças, sentimentos, interesses, expectativas, situações vivenciadas, etc.” 
Quadro 1: Questionário online.

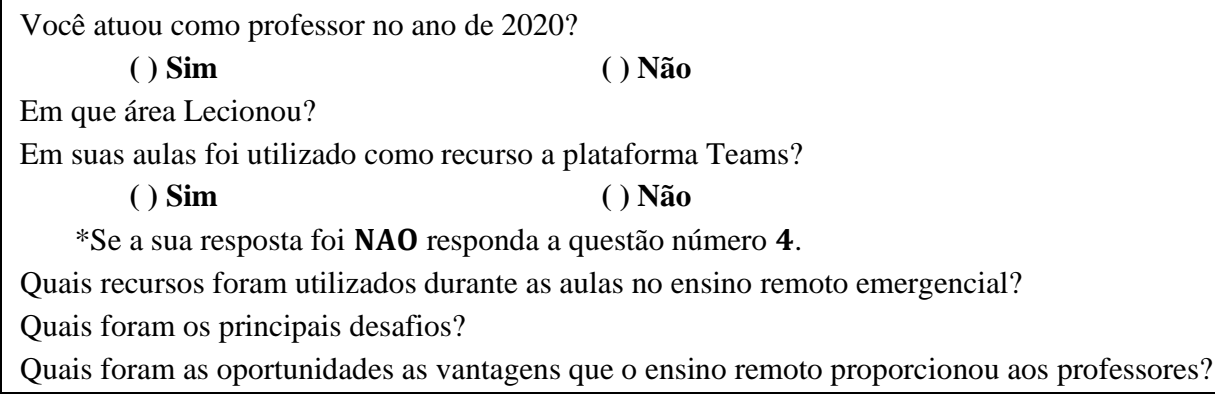

Fonte: Autores (2022).

A análise dos dados foi realizada de forma descritiva e interpretativa, utilizando o método indutiva (Bogdan \& Biklen, 1994), no qual foram analisadas as respostas obtidas íntegras, sendo preservada a identidade de cada participante e assim foram nomeando usando a nomenclatura P1, P2,...Pn, respectivamente, como previsto no termo de livre esclarecimento apresentado aos participantes da pesquisa.

Os resultados foram organizados e analisados em três subseções dos resultados e discussões, a saber: 3.1 Os diferentes recursos tecnológicos usados no ensino remeto pelo grupo de professores; 3.2 Desafios e oportunidades vivenciados no ensino remoto na visão dos professores e 3.3 Desafios do ensino remoto, respectivamente.

\section{Resultados e Discussão}

\subsection{Os diferentes recursos tecnológicos usados no ensino remoto pelo grupo de professores.}

Todos os professores que participaram da pesquisa lecionaram disciplinas na modalidade de ensino remoto no ano de 2020. No caso, esses professores usaram obrigatoriamente nas aulas remota o Ambiente Virtual de Aprendizagem (AVA) Microsoft Teams disponibilizado pela Secretaria do Estado de Mato Grosso (SEDUC), como sistema oficial. Na Figura 1 são apresentados os diferentes tipos de recursos utilizados durante o ensino remoto pelos professores. Porém, é observado que além da Plataforma Microsoft Teams outros recursos foram usados como aplicativo de mensagens e vídeos. Estes resultados sugerem que por ser um recurso novo para os professores e alunos a plataforma Microsoft Teams pode ter trazido dificuldades para alguns professores, que optaram pelo uso de outros recursos tecnológicos que tinham mais familiaridade.

Conforme foi apresentado no gráfico da Figura 1 o recurso mais utilizado pelos professores durante o ensino remoto foi o aplicativo whatsapp (42\%), muito provavelmente, devido este recurso ser mais utilizada no cotidiano mesmo antes do quadro pandêmico e do ensino remoto, consequentemente ser de fácil acesso para professores e alunos. Esta preferência por usar este recurso no ensino pode associada ao fato desta tecnologia fazer parte do dia a dia e pela versatilidade, tendo em vista que permite “a troca de vídeos, informações e discussões acerca da matéria estudada" na forma escriva e por áudio (Paczkowski \& Passos, 2019). Neste sentido o uso deste recurso pode aumentar a possibilidade das interações entre professor e aluno, podendo inclusive contribuir para o aumento da autonomia dos alunos nas atividades de Ensino, ou seja a tecnologia se torna uma aliada nos porcesos de Ensino e aprendiagem (Paczkowski \& Passos, 2019; Lima, et al. 2020; Valente, et al. 2020; Monteiro \& Nantes, 2021, Rossi, et al. 2021).

O segundo recurso mais utilizado pelos professores para ministrar as aulas foi o "AVA" Microsoft Teams (33\%), o qual foi disponibilizado pelo governo como recurso oficial para a oferta do ensino remoto. Além disso, 25\% assinalaram o uso de vídeos gravados, recurso esse muito utilizado nas aulas remota principalmente para aqueles alunos que não tinham acesso ao computador ou com dificuldades de manusear a plataforma Microsoft Teams, então os professores para amparar esses alunos nas aulas, muito provavelmente, optaram em gravar vídeos que podem auxiliar nas atividades de estudo (Figura 1). 
Figura 1: Relação das tecnologias utilizadas pelos professores durante o ensino remoto

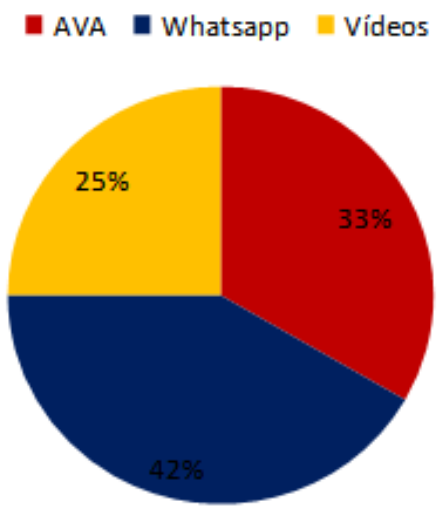

Fonte: Autores (2022).

Os resultados apresentados no gráfico acima (Figura 1) indica também que mesmo as aulas remotas ou o dito ensino remoto, seja considerada uma transmissão de aula em tempo real, onde o professor, da disciplina, está disponível para tirar dúvidas e fazer explicações sobre um assunto, nos mesmos horários da disciplina em que estariam acontecendo em modo presencial, o uso dos diferentes recursos tecnológicos mostram-se importantes para viabilizar a oferta de ensino (Paiva, 2020; Rondini, Pedro \& Duarte, 2020). Além disso, o uso destes diferentes recursos contribuiu para o melhor acesso do aluno as aulas e atividades ofertadas durante o ensino remoto, que certamente favoreceram a aprendizagem do aluno nesse momento de excepcionalidade vivenciado no ensino.

\subsection{Desafios e oportunidades vivenciados no ensino remoto na visão dos professores}

O ensino remoto emergencial teve também seus momentos de oportunidade, ou seja, seus momentos de aprendizagem que poderão ficar incorporados as práticas professores na visão dos participantes. Desta forma foi proposto aos professores que participaram da pesquisa relatar quais oportunidades eles tiveram no período do ensino remoto.

Tabela 1: Principais viabilidade relatados pelos professores.

\begin{tabular}{|c|c|}
\hline P1 & $\begin{array}{c}\text { Os meios tecnológicos são ferramentas com várias funções que bem instruída pode e poderá ser } \\
\text { um método muito vantajoso para os docentes e alunos, ou seja, de forma geral, um método inovador } \\
\text { que poderá trazer muitas oportunidades para a educação. }\end{array}$ \\
\hline $\mathbf{P 2}$ & $\begin{array}{l}\text { A vantagem é que pudemos dar continuidade as atividades pedagógicas e a desvantagem é que } \\
\text { aulas online não permitiu que todos os alunos participassem devido às condições financeiras. }\end{array}$ \\
\hline $\mathbf{P 3}$ & $\begin{array}{l}\text { Oportunizou conhecer e usar mais os recursos midiáticos, porém não vejo como vantagem, vejo } \\
\text { como um novo meio e recurso no ensino aprendizagem que precisa ser mais aprofundado, } \\
\text { entendendo que pode ser muito mais usual daqui para frente. }\end{array}$ \\
\hline $\mathbf{P 5}$ & $\begin{array}{l}\text { Conhecer melhor os pais dos alunos, reavaliar a sua forma de trabalhar em sala de aula, trabalhar } \\
\text { longe dos colegas e ao mesmo tempo estar perto através das reuniões via Teams. }\end{array}$ \\
\hline $\begin{array}{l}\text { Durante o ensino remoto foi possível conhecer novas tecnologias da informação e comunicação, } \\
\text { uma modalidade de ensino esquecida por muitos, como o ensino por meio de tecnologias digitais. } \\
\text { Auxiliou de forma obrigatória também a formação continuada dos docentes e profissionais da } \\
\text { educação, fazendo com que se atentem à biossegurança, higienização, EPI (equipamentos de } \\
\text { proteção individual), metodologias de ensino entre outros. }\end{array}$ \\
\hline
\end{tabular}

Fonte: Autores (2022).

Analisamos os relatos dos professores é observado que por mais que o ensino remoto tenha sido um período de dificuldades, obstáculos e preocupação teve oportunidade para novas aprendizagens, que os participantes entenderam como positivo, como relatou P2 ao afirmar que “A vantagem é que pudemos dar continuidade as atividades pedagógicas [...]”. Dessa 
forma, o ensino remoto foi um meio para que o ano letivo não fosse comprometido e assim daria continuidade as atividades curriculares.

O ensino remoto permitiu que os professores, alunos e familiares ficassem próximo mesmo estando longe, sendo realizado através da plataforma Microsoft Teams conforme é ressaltado pelo professor P4 "Conhecer melhor os pais dos alunos, reavaliar a sua forma de trabalhar em sala de aula, trabalhar longe dos colegas e ao mesmo tempo estar perto através das reuniões via Teams". Desse modo as aulas remotas foi uma surpresa tanto para os professores como para os alunos e familiares que tiveram que se unir para que desse certo o ensino remoto. Esses fatos passaram a fazer parte do cotidiano do aluno, da família e dos professores, revelando o que antes não era visto e, principalmente, tornando mais visível o lado mais humano dos processos de ensino (Paiva, 2020; Rondini, Pedro \& Duarte, 2020; Rossi, et al. 2021; Monteiro \& Nantes, 2021).

Também foi destacado pelos professores a oportunidade que o ensino remoto ofertou, ressaltando a importância da tecnologia na educação e como essa experiência demonstrou que novos recursos pudessem ser adicionados aos processos de ensino, conforme afirmam os professores P1 e P3:

"Os meios tecnológicos são ferramentas com várias funções que bem instruída pode e poderá ser um método muito vantajoso para os docentes e alunos ou seja de forma geral, um método inovador que poderá trazer muitas oportunidades para a educação" (P1, 2020).

"Oportunizou conhecer e usar mais os recursos midiáticos, porém não vejo como vantagem, vejo como um novo meio e recurso no ensino aprendizagem que precisa ser mais aprofundado, entendendo que pode ser muito mais usual daqui para frente" $(P 3,2020)$.

"Durante o ensino remoto foi possível conhecer novas tecnologias da informação e comunicação, uma modalidade de ensino esquecida por muitos, como o ensino por meio de tecnologias digitais. Auxiliou de forma obrigatória também a formação continuada dos docentes e profissionais da educação, fazendo com que se atentem à biossegurança, higienização, EPI (equipamentos de proteção individual), metodologias de ensino entre outros" (P5, 2020).

Ressaltam ainda que o uso dos recursos de tecnológicas foi de suma importância para o ano de 2020, pois foi através desse recurso que ocorreu a conclusão do ano letivo, conforme complementa P5. Analisando os relatos dos professores é observado que todos demonstraram ter entendimento similar sobre as oportunidades que foram ofertadas com o ensino remoto. $\mathrm{O}$ ensino remoto proporcionou aos professores aprofundar seus conhecimentos sobre as novas tecnologias, descobrindo um mundo virtual no qual existe vários recursos que podem ser usados para auxiliar os professores em vídeoaulas e Ambiente Virtual de Aprendizagem (AVA).

Portanto, nos relatos dos professores o tempo de pandemia e o ensino remoto ofertou recursos inovadores para o ensino, no entanto, eles foram pegos de surpresa sendo proposto o uso de novas tecnologias, dessa forma os professores se viram diante da necessidade de se capacitar, ou seja, voltaram a ser aluno para aprender ensinando. Dessa forma, os professores demonstraram nos relatos entendimento que esse período de pandemia proporcionou também qualificação para ofertar aos alunos o ensino que durante o distanciamento social devido a COVID-19 viabilizou aos alunos continuar os estudos.

Esses relatos vão encontro aos argumentos e reflexões de Rossi, et al. (2021), Lima, et al. (2021), Valente, et al. (2020) e Appenzeller, et al. (2020), que o ensino remoto trouxe "novos tempos" que exigiram dos professores nos diferentes níveis de ensino a reinvenção da forma de ensinar em tempo recorde e essas mudanças não foram fáceis, mais aprendizagem sobre o uso de recursos tecnológicos no ensino forma necessárias. Além disso, essas aprendizagens podem ser incorporadas nas práticas de ensino desse momento adiante, entretanto, observando a realidade da escola onde esses professores atuam. 


\subsection{Desafios do ensino remoto}

Baseando nos relatos dos professores foi possível observar os principais desafios vivenciados por eles durante o ensino remoto. Com base nos dados (Tabela 2) os principais desafios enfrentados pelos professores estão relacionados a participação dos alunos, uso da plataforma Microsoft Teams, produção de vídeoaulas e operação dos recursos tecnológicos como mostram o relatos reunidos na Tabela 2.

Tabela 2. Principais desafios relatados pelos professores

\begin{tabular}{|c|l|}
\hline P1 & $\begin{array}{l}\text { Um dos principais desafios foi participação dos alunos perante a plataforma Teams e a frequência } \\
\text { dos mesmos, o outro desafio está associado ao manuseio da Plataforma Teams, pois sabemos que a } \\
\text { mesma tem muito a oferecer, no entanto devido à falta de preparo e conhecimento a plataforma } \\
\text { acaba se tornando inutilizável para os docentes. }\end{array}$ \\
\hline P2 & $\begin{array}{l}\text { Pouca participação dos alunos, desinteresse dos mesmos, problemas com a plataforma Teams, sinal } \\
\text { de internet e falta de acompanhamento dos pais no processo escolar. }\end{array}$ \\
\hline P3 & Frequências dos alunos na plataforma e internet para os mesmos. \\
\hline P4 & Fazer videoaula, ficar longe da sala de aula e dos alunos. \\
\hline P5 & $\begin{array}{l}\text { Plataforma pesada, difícil para manter boa conexão, as ferramentas da plataforma também são de } \\
\text { difícil localização, plataforma estressante para uso quando não se tem uma boa orientação básica. }\end{array}$ \\
\hline
\end{tabular}

Fonte: Autores (2022).

Os professores enfatizam principalmente sobre a ausência e o desinteresse dos alunos comprometendo de certa forma a aprendizagem dos mesmos e não tendo um acompanhamento adequado devido as aulas serem de forma não presenciais e não terem os materiais adequados para as ambas as partes. A resposta do P2 ilustra bem, ao afirmar que: "Pouca participação dos alunos, desinteresse dos mesmos, problemas com a plataforma Teams, sinal de internet e falta de acompanhamento dos pais no processo escolar." O que também foi afirmado por P1e P3 destacando que um dos desafios foi a ausência dos alunos nas aulas online ministrada através da plataforma Microsoft Teams e a necessidade do uso da internet que muitas vezes estava oscilando a conexão e assim consequentemente prejudicava o aluno.

Já P4 mencionou que um dos grandes desafios foi "Fazer videoaula, ficar longe da sala de aula e dos alunos", uma vez que, optou por utilizar dos recursos tecnológicos para produzir vídeoaulas e disponibilizar na plataforma Microsoft Teams.

Nesse contexto, Honorato \& Marcelino (2020, p. 217), argumentam que o "ensino remoto emergencial" se tornou um obstáculo tanto para aluno como para professores por ser um ensino com metodologias novas, "algo que se tronou complexo" devido não estar preparado para a mudança da sala de aula para os meios tecnológicos, destacando ainda que as o ensino remoto não permite que os professores desenvolvam todas as estratégias que seria possível desenvolver em sala. Soma-se a esses desafios o fato de muitos professores terem tido pouco tempo para aprender a usar essas tecnologias e pouco conhecimento sobre as metodologias que são recomendadas para uso no ensino online, o "ensino remoto" (Paczkowski \& Passos, 2019; Lima, et al. 2020; Valente, et al. 2020; Monteiro \& Nantes, 2021, Rossi, et al. 2021).

Ainda sobre os desafios, cabe observar os relatos de P1 que ressalta sobre as dificuldades no uso da plataforma Microsoft Teams e a inexperiência de meios tecnológicos que foram necessários para o preparo de cada aula. Ele ainda destaca que a plataforma Microsoft Teams tem muito a oferecer, porém devido o "despreparo" e a "falta de orientação" obtida ao manusear, a plataforma acaba se tornando pouco explorada pelas ambas as partes (professores e alunos. No mesmo sentido P5 relata que a "Plataforma [Microsoft Teams] pesada, difícil para manter boa conexão, as ferramentas da plataforma também são de difícil localização, plataforma estressante para uso quando não se tem uma boa orientação básica”, demonstrando que embora haja um esforço para usar os recursos disponibilizado pela plataforma a falta de formação se mostra ainda ser um problema. 
"Um dos principais desafios foi participação dos alunos perante a plataforma Teams e a frequência dos mesmos, o outro desafio está associado ao manuseio da Plataforma Teams, pois sabemos que a mesma tem muito a oferecer, no entanto devido à falta de preparo e conhecimento a plataforma acaba se tornando inutilizável para os docentes " (P1, 2020).

"Plataforma pesada, difícil para manter boa conexão, as ferramentas da plataforma também são de difícil localização, plataforma estressante para uso quando não se tem uma boa orientação básica” (P5, 2020).

Analisamos os relatos dos professores que participaram da pesquisa torna-se perceptível que algumas preocupações foram recorrentes como o desinteresse dos alunos, dificuldades em fazer uso dos recursos oferecidos pela plataforma Microsoft Teams, produção de vídeoaulas e conexão de internet. Esses relatos refletem bem o conceito básico o ensino remoto, que remete ao um ensino ofertado "praticamente" por "improviso" ou pela tentativa de transposição da aula tradicional que antes era ministrada no presencial para a versão online. Entretanto, trabalho no ensino a distância requer formação para uso dos recursos tecnológicos, conhecimentos de metodologias de ensino e conhecimento sobre a operação de equipamentos eletrônicos necessários a realização da oferta do ensino (Médici et al., 2020; Lima, et al. 2020; Moreira et al., 2020; Carneiro, et al. 2020; Monteiro \& Nantes, 2021; Rossi, et al. 2021).

E nas para lavras dos participantes, muito embora houvesse a disposição dos professores na oferta do ensino remoto a formação transpareceu ser um dos principais desafios durante esse período. Entendemos, há de ser considerado que o "novo", que nesse caso representa o ensino remoto, pode provocar medo, estresse e insegurança, porque muito embora as tecnologias digitais fazerem parte do cotidiano de professores e alunos, elas eram vistas até então como lazer, fonte de informação e em situações mais raras como instrumento de trabalho. Nesse contexto, o ensino remoto colocou essas tecnologias digitais no centro das práticas de ensino para o professor e do aprender para os alunos. Nesse sentido, Appenzeller, et al. (2020) argumenta que o ensino remoto "novos tempos" e junto trouxe "novos desafios", ou seja, os professores e a escola tiveram que se adaptarem a realizada, inclusive tendo que consideram a realidade local onde se encontra inserida.

\section{Considerações Finais}

O presente estudo mostrou que o ensino remoto trouxe oportunidades que na visão dos professores referem-se a aprendizagem sobre o uso de tecnologias digitais para o ensino, devido a oferta de formação. E na visão dos professores mesmo que a formação continuada para uso dos recursos tecnológicos no ensino remoto tenha sido curta e ainda terem restados dúvidas durante as aulas, ainda assim, essa aprendizagem foi vista como positiva.

Por outro lado, os principais desafios foi aprender a usar os recursos digitais, ofertar o ensino no ensino remoto, ter a participação e assiduidade dos alunos nas aulas. Dentro desse contexto, de desafios a conexão de internet se mostrou um desafio para professores e alunos durante as aulas remotas e de certa forma revela esse gargalo que não parece ser uma particularidade vivenciada por esse grupo de professores.

Por fim, finalizamos ressaltando que os relatos dos professores fazem acreditar que todo esforço não foi em vão, pois o desafio de ensinar faz parte da profissão e que a volta do ensino na forma presencial é o que possibilita proporcionar um ensino melhor para os alunos. Além disso, o ato de ensinar é visto como uma forma de expressar o amor, o professor não desisti da profissão, pois acredita no futuro de seus alunos que somente a educação pode oferecer.

Para estudos futuros, certamente será relevante estudar a continuidade do uso dos recursos tecnológicos em situação de ensino por esses professores, tendo em vista, que muitos estudos discutem a apropriação das habilidades desenvolvidas no contexto da pandemia da COVID-19 serem ou não incorporadas as práticas de ensino quando retornar o ensino presencial.

\section{Agradecimentos}

A todos do PPGECM/UNEMAT e a todos os participantes da pesquisa. 


\section{Referências}

Appenzeller, S., Menezes, F. H., Santos, G. G. D., Padilha, R. F., Graça, H. S., \& Bragança, J. F. (2020). Novos tempos, novos desafios: estratégias para equidade de acesso ao ensino remoto emergencial. Revista Brasileira de Educação Médica, 44(1), e0155. https://doi.org/10.1590/1981-5271v44.supl.120200420 .

Bogdan, R. C., \& Biklen, S. K. (1994). Investigação qualitativa em educação: uma introdução à teoria e aos métodos. Porto Editora.

Bunchaft, A. F., \& Gondim, S. M. G. (2004) Grupos focais na investigação qualitativa da identidade organizacional: exemplo de aplicação. Estudos de Psicologia (Campinas), 21(2), 63-77. Disponível: https://www.scielo.br/j/estpsi/a/BsYfScPyHYSrCFwQqsLBYxg/?format=pdf\&lang=pt.

Fiorentini, D., \& Lorenzato, S. (2006). Investigação em educação matemática: percursos teóricos e metodológicos. (3a ed.), Autores Associado.

Freire, P. (1993). Pedagogia da Autonomia. (25a ed.), Paz e Terra.

Gadotti, M. (1999). História das ideias pedagógicas. (8a ed.), Ática.

Gil, A. C. (2008). Métodos e Técnicas de Pesquisa Social. (6a ed.), Atlas.

Honorato, H. G., \& Marcelino, A. C. K. B. (2020). A arte de ensinar e a pandemia COVID-19: a visão dos docentes. REDE-Revista Diálogos em Educação, 1(1), 208- 220. http://faculdadeanicuns.hospedagemdesites.ws/ojs/index.php/revistadialogosemeducacao/article/view/39/18.

Lima, A. R.Q., Lima, H. F., Souza, F. V., Silva, F. G., Lima, M. R., Zaranza, M. T. C., \& Sacramento R.A. L. (2020). Tecnologia aliada à educação: um Estado do Conhecimento sobre o celular como recurso didático em sala de aula. Research, Society and Development, 9(9), e274997249. https://doi.org/10.33448/rsd-v9i9.7249.

Médici, M. S.; Tatto, E.R. \& Leão, M. F. (2020). Percepções de estudantes do Ensino Médio das redes pública e privada sobre atividades remotas ofertadas em tempos de pandemia do coronavírus. Revista Thema, 18(ESPECIAL), 136-155. http://dx.doi.org/10.15536/thema.V18.Especial.2020.136-155.1837.

Milani Júnior, J., \& Carvalho, J. W. P. (2020). AnReQuim: um recurso digital para o ensino de química. Revista Signos, 41(2). http://dx.doi.org/10.22410/issn.1983-0378.v41i2a2020.2573.

Monteiro, A.; Moreira, J. A. \& Almeida, C. (2012). Educação online: Pedagogia e aprendizagem em plataformas digitais. DeFacto Editores.

Monteiro, E. S., \& Nantes, E. A. S. (2021). O letramento digital como estratégia de ensino-aprendizagem no ensino superior, durante o ensino remoto emergencial. Research, Society and Development, 10(10), e03101018576-e03101018576. http://dx.doi.org/10.33448/rsd-v10i10.18576.

Neves, M. E. R.N., Carvalho, J. W. P., \& Kapitango-a-Samba, K. K. (2019). Objetos digitais de aprendizagem como recurso mediador do ensino de química. Revista Cocar, 13(27), 1005-1021. https://periodicos.uepa.br/index.php/cocar/article/view/2882.

Neves, V. N. S.; Assis, D. \& Do Nascimento, S. R. (2021). Ensino remoto emergencial durante a pandemia de COVID-19 no Brasil: estado da arte. Práticas Educativas, Memórias e Oralidades-Rev. Pemo, 3(2). e325271-e325271. https://doi.org/10.47149/pemo.v3i2.5271.

Oliveira, F. C. D. O., \& Carvalho, J. W. P. (2020). QuiLegAl application as a teaching resource fromthe perception of undergraduate Chemistry students. Actio: Docência em Ciências, Curitiba, 3(3), 1-2. 10.3895/actio.v5n2.9326.

Oliveira, F. C., Souto, D. L. P., \& Carvalho, J. W. P. (2018). Percepções e apontamentos de um grupo de discentes ao explorarem a hipermídia Equimídi@. Revista Brasileira de Ensino de Ciência e Tecnologia, 11(2), 146-168. 10.3895/rbect.v11n2.5955.

Oliveira, F. C.; de Paiva, M. M.; Alves, L. E.; da Silva Lorim, C.; da Silva, F. S. \& Carvalho, J. W. P. (2021). QUILEGAL: Um recurso para o ensino de Ciências Naturais. South American Journal of Basic Education, Technical and Technological, 8(2), 707-730. https://periodicos.ufac.br/index.php/SAJEBTT/article/view/4216/3148.

Paczkowski, I. M. \& Passos, C. G. (2019). Whatsapp: uma ferramenta pedagógica para o ensino de Química. RENOTE, 17(1), 316-325. https://doi.org/10.22456/1679-1916.95799.

Paiva, V. L. M. O. (2020). Ensino remoto ou ensino a distância efeitos da pandemia. Estudos Universitários: Revista de Cultura, 37(1), 58-70. https://periodicos.ufpe.br/revistas/estudosuniversitarios/article/view/249044/37316.

Pascoin, A. F. \& Carvalho, J. W. P. (2020). Objeto digital de aprendizagem como proposta pedagógica para o ensino de química. Revista Eletrônica Científica Ensino Interdisciplinar, 6(17). DOI:10.21920/recei72020617438452.

Rondini, C. A; Pedro, K. M.; Santos D. C. (2020). Pandemia do Covid-19 e o ensino remoto emergencial: Mudanças na práxis docente. Interfaces CientíficasEducação, 10(1). 41-57. https://doi.org/10.17564/2316-3828.2020v10n1p41-57.

Rossi, M.; Braun, P. D. L.; Carvalho, J. W. P.; De Miranda, A. F. \& Mello, G. J. (2021). Desafios enfrentados por pedagogas na utilização de uma nova plataforma: aulas remotas em tempos de pandemia da COVID-19. Research, Society and Development, 10(14), e466101421753-e466101421753. https://doi.org/10.33448/rsd-v10i14.21753.

Valente, G. S. C., de Moraes, É. B., Sanchez, M. C. O., de Souza, D. F., \& Pacheco, M. C. M. D. O ensino remoto frente às exigências do contexto de pandemia: Reflexões sobre a prática docente. Research, Society and Development, 9(9). e843998153-e843998153. https://doi.org/10.33448/rsd-v9i9.8153. 